\title{
Congenital Tuberculosis
}

\author{
Chatterjee $\mathbf{N}^{1}$
}

\begin{abstract}
A two month old baby born to a mother suffering from fever and backache since last four months, presented with huge hepatosplenomegaly, ascites and pallor. USG and CT-scan showed hypoechoic shadows in liver, spleen and abdominal lymph nodes and FNAC revealed acute-on-chronic inflammation of liver that suggested Congenital Tuberculosis. Investigations in mother revealed Pulmonary Tuberculosis and Caries Spine, confirming the diagnosis of Congenital Tuberculosis in the baby.
\end{abstract}

Key words: Congenital TB, hepato-splenomegaly, abdominal lymphadenopathy

\section{Introduction}

C ongenital TB is conspicuously rare in spite of tuberculosis being a common disease worldwide and tubercular disease in pregnant women not being uncommon at all. This is possibly due to the placental barrier in transmission ${ }^{1,2}$. Only 300 cases had been reported worldwide till 1989, then over the next 5 years another 58 cases were reviewed. Between 2001-'05 only 18 cases have been reported ${ }^{2}$. We present here a case of congenital tuberculosis with systemic manifestation, born to a mother with disseminated Tuberculosis.

\section{The Case}

A two month old male child presented with progressive swelling of the abdomen from one month of age and fever for the last 15 days. He was born by vaginal delivery, at term, with birth weight of $2.6 \mathrm{~kg}$ and an uneventful perinatal period. The baby was exclusively breast fed and did not received any immunization. On examination he had severe pallor but no cyanosis, oedema, jaundice, tachycardia, tachypnea or respiratory distress. At two months he weighed 4.3 $\mathrm{kg}$, with length $56 \mathrm{~cm}$ and head circumference $37 \mathrm{~cm}$. There was huge abdominal distension with tense ascites. Abdominal veins were prominent with flow away from the umbilicus. Liver was palpable 6 $\mathrm{cm}$ below costal margin (span $9 \mathrm{~cm}$ ) and firm consistency. Spleen was also palpable $5 \mathrm{~cm}$ below left costal margin. Chest auscultatory findings were normal.

On investigation, blood picture showed $\mathrm{Hb}-5.6 \mathrm{gm} / \mathrm{dl}$, with anisopoikilocytosis, microcytosis and reticulocyte count $4.2 \%$.
'Dr. Nandita Chatterjee, MBBS, DCH, DNB, Professor of Paediatrics, Vivekananda Institute of Medical Sciences, RKM Seva Pratishthan, 99, Sarat Bose Road, Kolkata 700026, India.

\section{Address for correspondence:}

Dr. Nandita Chatterjee

E-mail: chattnan@gmail.com

\section{How to cite}

Chatterjee N. Congenital Tuberculosis. J Nepal Paediatr Soc 2014;34(2):144-146.

doi: http://dx.doi.org/10.3126/jnps.v34i2.10910

This work is licensed under a Creative Commons Attribution 3.0 License.

(c) (i)

Total WBC count was $4600 /$ cumm with N60, L35, M2, E3, platelet-88000/cumm, ESR-60. Blood biochemistry revealed urea-23, creatinine-0.5, Na-138, K-4.1, total bilirubin-2.2, conjugated-1.0, total protein-5.8, albumin-2.8, globulin-3.0, SGPT16, SGOT-29, ALP-255, all within normal limits, indicating normal liver function, though Coagulation profile showed some alteration with Prothrombin Time: 33.4 (Control: 11), APTT 46.9 (Control:28) and INR-3.21.. CRP level was 24, showing a higher than normal value ( $\mathrm{N}: 6)$.

With an initial diagnosis of septicaemia with pallor, we gave a course of antibiotics and packed cell transfusion, with no clinical improvement.

X-ray abdomen and chest showed distended bowel loops, enlarged liver, 
normal sized heart and mild infective changes in right mid zone of lung (Fig 1).

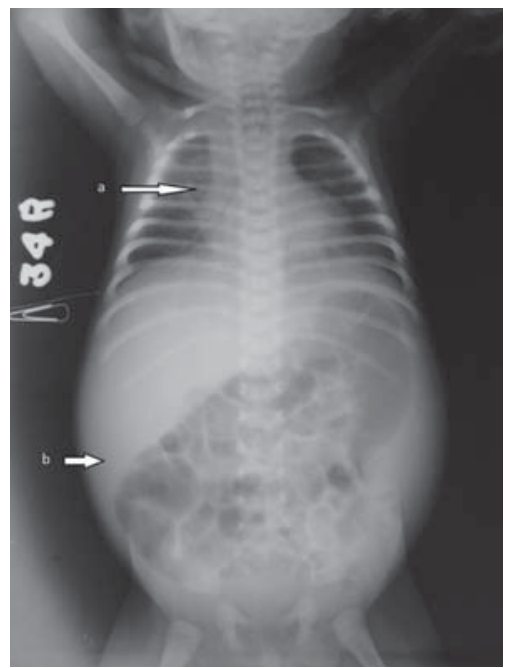

Fig 1: X-ray Chest and Abdomen showing (a) mild infective changes in right mid zone of lung, (b)enlarged liver, distended bowel loops and normal sized heart.

USG abdomen showed hepatosplenomegaly with multiple hypo echoic lesions, suggesting a multi cystic lesion, in both liver and spleen with ascites (Fig 2). There were no features of portal hypertension.

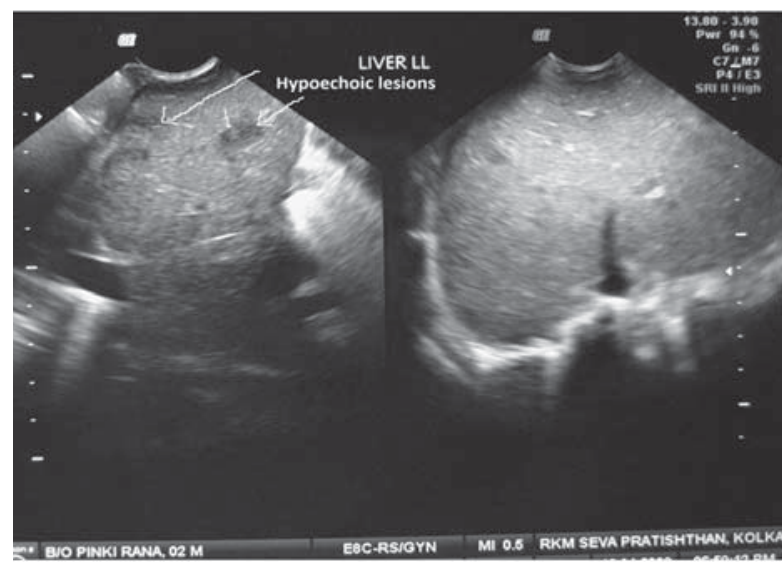

Fig 2: USG abdomen showing hypo echoic lesions in the liver.

USG guided FNAC of liver revealed a picture of acute-on-chronic inflammation with mixed inflammatory cells and histiocytes and epitheloid cell granulomas.

CT scan abdomen revealed hepatosplenomegaly with pre and para aortic lymphadenopathy with multiple hypo dense lesions in these organs, possibly necrotic areas (Fig 3).

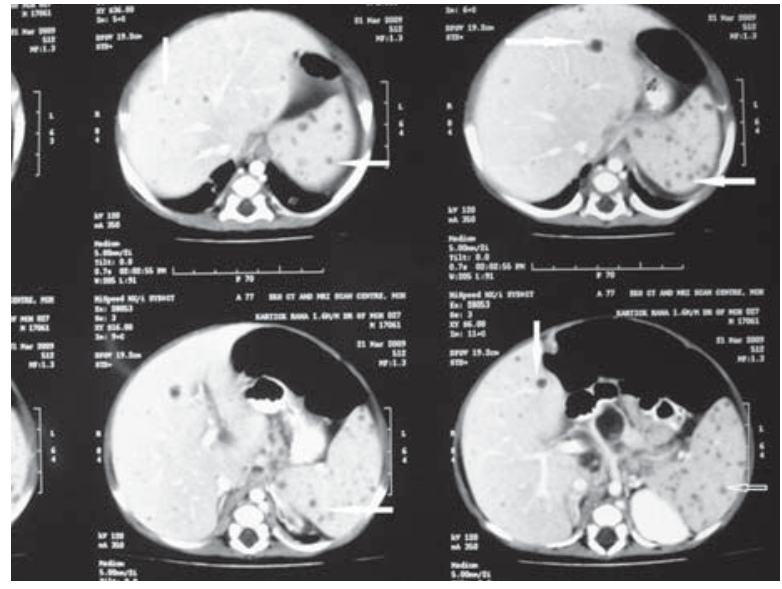

Fig 3: CT Scan of abdomen showing multiple hypodense lesions in liver and spleen.

Ascitic fluid was found to be exudative in nature (cell count-1600/cumm, 90\% lymphocytes). No organism was detected on Gram stain and AFB stain. Ascitic fluid was positive for Adenosine Deaminase level (56 IU).

Mantoux test $(1 / 1000)$ was negative. CSF study of the child was normal. Routine examination of urine was normal and culture was sterile.

Necrotic lesions in liver and spleen with FNAC suggesting chronic inflammation and exudative type of ascitic fluid with lymphocyte predominance suggested a diagnosis of Tuberculosis, possibly of congenital nature.

The mother gave a history of irregular antenatal checkup, episodes of low grade fever in her last two months of pregnancy. On examination, the mother revealed a thin build, mild pallor and a prominent gibbus at D 8-10 segment with mild tenderness and no weakness of limbs. Chest X-ray showed blunting of left costophrenic angle with mediastinal lymphnodes (Fig 4). Lateral X-ray chest showed collapse of D8-10 vertebrae. Mantoux reaction in the mother was $12 \mathrm{~mm}$ induration. ELISA for HIV was negative.

Four drug ATT was started for both mother and child with additional steroid for the child and both mother and baby were salvaged. According to the IAP consensus $^{3}$ the child showed remarkable improvement within one month of treatment, with disappearance of ascites and reduction in liver and spleen size, along with improvement in general well being and weight gain. 


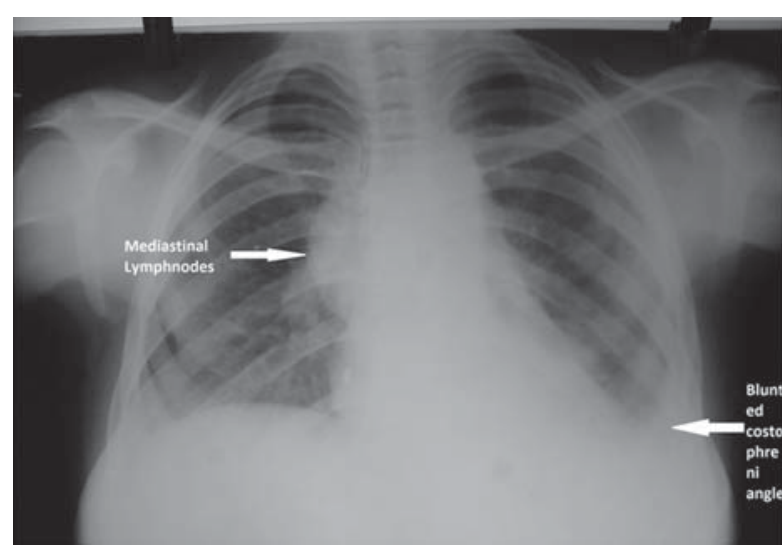

Fig 4: X-ray Chest of mother showing enlarged mediastinal lymphnodes and blunting of left costophrenic angle.

\section{Discussion}

Congenital TB is acquired either by transplacental spread via umbilical vein or aspiration or swallowing of infected material. In the former case primary focus is in the liver with involvement of periportal lymphnodes ${ }^{1}$. A baby with congenital TB generally has non-specific features and may present weeks after birth ${ }^{4,5,6}$, hence diagnosis may easily be missed unless index of suspicion is strong. Fever, hepatoslenomegaly and lymphadenopathy are common findings, but ascites is a rare presentation, two cases were reported with ascites out of 58 reviewed ${ }^{4,7}$. A similar case as ours was reported by Rajiv Kumar et al from New Delhi in $2005^{7}$.

A history of maternal TB, generalized symptoms in baby like fever and hepatomegaly ${ }^{1}$ not responding to standard treatment and evidence of primary lesion in the liver should prompt the diagnosis of congenital TB. In our case clinical suspicion in the index case prompted us to investigate the mother and proof of active lesion in mother clinched our diagnosis of Congenital Tuberculosis. Mothers generally suffer from TB in pregnancy with rapidly progressive disease with hematogenous dissemination or with recent primary infection. In the former case, as with our patient, miliary lesions are expected in the placenta, from where the infection spreads to the fetus ${ }^{2}$. Histopthological examination of the placenta ${ }^{1,2}$ would have been helpful had the mother been diagnosed antenatally.

Mantoux test is not a reliable measure, as a negative test is often documented. Hageman's study showed only two out of fourteen cases were MT+ve ${ }^{8}$. We established our diagnosis according to Cantwell's revised criteria of $1994^{2}$, where a primary hepatic complex or caseating hepatic granuloma is diagnostic. This revised criteria has better diagnostic sensitivity and emphasizes on evaluating mothers of suspected infants, thus promoting detection of the disease hitherto hidden in the mother, as in our present case.

\section{References}

1. Seth V, Kabra SK. Congenital Tuberculosis. In: Esentials of Tuberculosis in Children. ( $3^{\text {rd }} \mathrm{Edn}$ ) New Delhi, Jaypee Brothers Publication 2006; 295-303

2. Cantwell MF, Shehab ZM CostelloAM,et al. Brief report:Congenital Tuberculosis. N Engl J Med 1994;333:1051-4

3. Treatment of Childhood Tuberculosis, Consensus statement of IAP working group. Indian Pdiatr 1997;34:1093-6.

4. Abhughani N, Van de Kuyp F, Annable W et al. Congenital Tuberculosis. Indian Pediatr 1980;18:376-79.

5. Smith MHD, Teele DW. Tuberculosis acquired in utero. In Remington JS, Klein JO (Eds) In infectious Diseases of Fetus and Newborn( $4^{\text {th }}$ Edn)Philadelphia, WB Saunders Publication 1995; 1077-80

6. Balasbramanian S, Shivram R, Padmasani LM etal. Congenital Tuberculosis. Indian J Pediatr 1999;66:148-50.

7. Kumar R, Gupta N, Subharwal A, et al. Congenital Tuberculosis. Indian J Pediatr 2005;72(7):631-633.

8. Hageman J, Shulman $S$, Schreiber $M$, et al.Congenital Tuberculosis: critical reaoppraisal of clinical findings and diagnostic procedures. Pediatrics 1980;66:980-84 